\title{
Complicações Após Cirurgia de Varizes
}

Silva JE. ${ }^{1}$

${ }^{1}$ Belo Horizonte - Brasil.

E-mail: josualdo.euzebio@yahoo.com.br

Silva, J.E. 2013. Complicações Após Cirurgia de Varizes, p.37. In: Bastos, Francisco Reis. Anais do V Simpósio Internacional de Flebologia [Blucher Medical Proceedings n.1 v.1]. São Paulo: Blucher, 2014

http://dx.doi.org/10.5151/medpro-flebo-SIF_18
As varizes constituem uma doença muito prevalente, e o tratamento cirúrgico, já consagrado, é amplamente realizado pelos cirurgiões vasculares, sendo a cirurgia vascular mais realizada.

Dentre as abordagens cirúrgicas temos as técnicas de fleboextração e as ablações térmicas, seja com uso do laser ou radiofrequência.

A boa formação dos cirurgiões vasculares, nas residências e educação médica continuada; simpósios, reuniões clinicas, congressos tem em muito contribuído para a redução das complicações.

Mostrarei nesta aula as complicações mais frequentes, com o objetivo de deixar a todos uma reflexão sobre esta cirurgia muito realizada, e que exige atenção e muita cautela na indicação, realização e acompanhamento pós-operatório.

Palavras chave: varizes, cirurgia de varizes, varizes complicações. 